for the mere necessities of calculation to act. All his argument, if I understand it aright, depends upon the displacement being by fits and starts. Thus he says (NATrRE, July 28, I870), "The precessional force has its full effect in producing the precession of the solid crust, the fuid not having time * to diminish that effect before the axis has assumed a new position;" and "The friction of the fluid within, which has not time to influence the nutation before the nutation is actually produced;" and (NATURE, May I1, I87I), "Suppose a succession of slight horizontal pushes to be given to the poles in a continually altering direction, the effect will be that the revolving crust will be continually slipping over the revolving fluid, which has not time to acquire the new motions given instantaneously to the solid crust."

The leading idea in all these passages seems to me to be that the attractions of the sun and moon, to which precession and nutation are owing, act by impulses, by a succession of sharp pulls quickly repeated. This is truly enough the supposition with which mathematical calculation starts; but the real action, I need not say, is a steady, continuous, though ever varying, pull, and it is the result of such an action which our calculations in the end lead us to, by a method which enables us to get rid of the error necessarily involved in the approximate result which would follow from our first supposition.

I cannot then help thinking that even Archdeacon Pratt has for once been carried away by the beauty of mathematical analysis, and has for the moment forgotten that the conditions which it is obliged to employ for its ends do not in their initial form represent the actual conditions of nature. The explanation occurred to me on first reading his paper in the Philosophical Magazine, but seemed to me so unlikely that I shrank from putting it forward. I can, however, in no other way imagine how he can have come to the startling conclusion, that, if a solid shall be moved by a steady, continuous pull over an interior ball of fuid, it can make no difference in the result, whether there is or is not friction between the interior of the shell and the surface of the fluid. Archcleacon Pratt, will, I know, if I am wrong, pardon my presumption and put me right.

$$
\text { Barnsley, May iz }
$$

$$
\text { A. H. GREEN }
$$

\section{Pangenesis: Graft-Hybrids}

EACH person who assails this unfortmate "provisional hypothesis" makes the attack from his own particular point of view. Thus, in NATURE of last week Prof. L. S. Beale, as a microscopist, objects to it because the gemmules camnot be made evident to the senses. From this somewhat narrow view of the case the atomic theory of chemistry, the undulatory theory of light, or the mechanical therry of heat, must all break down, for no one has as yet seen an ultimate atom, or an ethereal undulation. Mr. A. C. Ranyard, in the same paper, publislies a letter which is quite at variance with fact, for if he will turn to pp. $390,39 \mathrm{I}, 394,397$ in vol. i. and pp. 364 and 365 vol. ii. of Mr. Darwin's work on "The Variation of Animals and Plants under Domestication," he will there find many cases given of the scion affecting the stock and producing intermediate forms lnown as "graft-hybrids." Pangenesis has not yet "received its death blow."

R. MEldola

\section{May 13}

IN your last number Mr. Ranyard brings forward an objection to Mr. Darwin's theory of Pangenesis on the ground that the grafting of a bud on a stock of a different species does not produce a bybrid offspring. I am not about to defend the doctrine of Pangenesis, which appears to me incapable alike of proof and of disproof. It is, however, a well-known fact that the stock dues affect the scion, and vice versâ. In Pruf. Henfrey's "Flementary Course of Botany" (Dr. Masters's edition) he says, "A certain amount of physiological influence of the stock over the scion is shown to exist by such facts of horticultural experience as that the fruit of the pear is smaller and more highly coloured when 'worked on' the quince and medlar than when grafted on pear-stocks, and is earlier when worked on the mountain-ash." The well-known instances of the communication of variegation from the scion to the stock in Abutilon, recorded by Prof. Morren and others, are considererl cases of contanious disease; tut what is the theory ot contagion but that the blood or other

* I have taken the liberty of italicising those expressions which seem to me of vital importance to the argument in these quotations. "fluid" of an animal or plant is affected by emanations, call them "gemmules" or what you will, from another individual? The same writer records an instance which he considers well authenticated of the production of the hybred Cytisus Adami by the grafting of $C$. purpureus on C. laburnum.

\section{ALFRED W. BENNETT}

The Rev. Mr. Highton and Thermodynamics

You are cruelly kind to $\mathrm{Mr}$. Highton in giving him space to develop his absurdities.

His new remarks on Joule, like his earlier ones on a paper by Sir W. Thomson, simply show that ke aroes not zinderstand what he ventures to criticise. Of course, what Joule now says is precisely what he said a quarter of a century ago, with the simple difference that it is put in a somewhat more popular form.

No one who has taken the trouble to understand the experimental facts and the elementary reasoning of which the laws of Thermodynamics are the condensed expre sion, has any more doubt of their trith than of the truth of Newton's Laws of Motion. They are, perhaps, a little harder to understand; but the proof is of the same nature, and already almost of the same extent, in the newer science as in the older one.

I have not seen the Reviez of Popular Science refeired to by Mr. Highton, but I hope (for the credit of that journal) that he misconceives its statements as he does those of Jou'e.

Your "first reviewer" (or rather précis-writer) of his article, whoever he may be, certainly gives him no encouragement in the number for Jan. 19, whatever may have been the effect of my treatment of his not singular case.

\section{YoUR REVIEWER}

\section{On the Radial Appearance of the Corona}

Wout. an indefinitely extending solar atmosphere, if its existence could be proved, be in itself sufficient to explain the appearance of the solar corona? Should we not still have to explain the apparent radiation which is so distinctly part of the phenomenon?-If the light or heat of the sun which radiates symmetrically outwards as from a point at its centre be the cause of the illumination, surely the figure of the corona would bear some relation to the figure of the atmosphere or medium on which the light or heat acts? Yet I think I may say that it is quite impossible to conceive a medium so distributed and arranged as to form rays such as those seen in the crrona. If the recent photographs had not shown beyond a doubt that this irregular radiating appearance belongs to the corona and the neighbourhood of the sum, " it would have gone a long way to prove that the corona is at least partly due to the earth's atmosphere or mere opical effect. But, as it is, I think this radiation clearly proves that the corona cannot be due to the direct action of the light and heat of the sun on any surrounding matter. In fact, I cannot cimceive an atmusphere the character of which varies in a radial manner, however rapidly either its nature or densily may vary with the distance from the surface of the sun. If, instear of an atmosphere, we try to conceive a ring of meteors, still the radial gaps so clearly marked on the photographs present insurmountable difficulty. This, mor eover, is impossible on other grounds. It is impossible that there can be an almost homogeneous mass of meteoric matter circulating round the sun in the form of an outer sphere, and if it circulated in the eclipic or any other plane, it would present the appearance of Satum's belt, whereas the cotona appears altogether clifferent trom this, and cannot possibly be a film of light in any plane but that of the sun's limb.

Nor can these raclial rifts be of the nature of sladow. For the shadow which anything like a sun spot wiuld produce in a misty atmosphere must be conical, the veriex of the rone being outwaris, so that the edges of the sliadow would approach each other instead of receding as they do. Moreover. such a shadow would still be seen through a great extent of illuminated so ar atmo sphere, and therefore be only partial or faint, whereas the ritts are so dark and definite as to imply a total absence of corunal light ; this must be the case unless the rifts or gaps in the spherical envelope extended right across the sphere from front to back, and we know that there is ro obstruction on the surface of the sun tha! could cast such an extensive shadow.

What, then, does this rediated appearance thow the corona to be? I think that it proves that the corona is an emission either of illuminated matter or of an action illuminatung matter,

$$
\text { * Has this yet been established ?-ED. }
$$

